\title{
John Cage as a Hörspielmacher Richard Kostelanetz
}

Poets should emphatically be brought into the wireless studio, for it is much more conceivable that they should be able to adapt a verbal work of art to the limits of the world of space, sound and music. The film demands the visual artist who has also a feeling for words; the wireless on the other hand needs a master of words who has also a feeling for modes of expression appropriate to the sensuous world.

- Rudolf Arnheim

Radio: An Art of Sound (1936)

FEW NATIVE-BORN ARTISTS realize the ideal of true polyartistry as completely as John Cage, who has not only changed music but, by my count, has made substantial contributions to American literature, theater and perhaps visual art, extending in all his radical esthetic preference for nonfocused, nonhierarchic, uninflected art. Thus, it is scarcely surprising that late in the seventh decade of his productive life he has occupied yet another artistic terrain, a terrain so unfashionable that, its familiarity notwithstanding, it has no critics and few rewards-radio.

Given the low status of Art in American radio, it is no surprise that Cage has done most of this work in Europe, initially for Westdeutscher Rundfunk in Cologne. These radio works are produced not by WDR's music department, which nonetheless airs transcriptions of Cage's music, but by Hörspiel which translates literally as "ear-play" and is, in the German radio bureaucracies, a production department distinct from literature and feature.

In Germany, Hörspiel has traditionally meant radio plays, which were customarily not soap operas or comedies (as we know from American radio), but something else-poetic texts, indefinite enough to stimulate the listener's imagination, whose words are read by well-cultivated voices, recorded in a studio, abetted by minimal sound effects. In American radio, the closest analogue was Archibald MacLeish's Fall of the City (1938); perhaps the most famous English-language radio play of this kind is Dylan 
Thomas's Under Milk Wood (1953). Since Hörspiel as a word is far more graceful and encompassing than any English equivalent, I will henceforth use it without italics or umlaut, as though it were an English word.

Two cultural products that Germans value far more than we are opera and horspiel. For the latter, there are annual prizes, the most prestigious being the Hörspielpreis der Kriegsblinden (or war-blind). Horspiels are also collected into textbooks that are taught in the universities and gymnasia. Anthologies and critical books are frequently published; current critical issues are discussed at annual conferences. There is even a prodigious encyclopedia, now outdated, with the unfortunate title of Hörspielfiuhrer. Twice a year Westdeutscher Rundfunk issues a book-length catalogue of forthcoming productions, most of which are displayed on a full 8" by 8" page. In each of these WDR books is more Radio Art than America has ever produced. Showing a recent volume to an American radio professional is to watch him faint dead away.

Within the past two decades, a producer on WDR's permanent staff, Klaus Schöning, developed a distinct alternative to traditional German horspiel. Interested in sound as well as in words, he turned first to the great European experimental poets, such as Ernst Jandl and Franz Mon, Gerhard Rühm and Ferdinand Kriwet, as well as the composers Mauricio Kagel and, later, Clarence Barlow-in Arnheim's phrases, masters of words with a sensitivity to aural expression. Schöning called this more acoustic work Neue Hörspiel, and in his pioneering anthology of that title (1969) all those Hörspielmachers (except Barlow, who is younger) are represented. Where radio plays had previously defined an intermedium between literature and theater, Schöning gravitated to points between literature and music. Indicatively, the surest measure of his success, in his colleagues' eyes, is not how many listeners he has but how many horspiel prizes his artists have won.

Even though Schöning did not enter Cage's life until 1978, the latter had a long creative interest in radio and its principal storage medium (audiotape). His Imaginary Landscape No. 1 (1939) was written, to quote his publisher's catalogue, for "two variable-speed phono-turntables, frequency recordings, muted piano and cymbal; to be performed as a recording or broadcast." Two details perhaps unfamiliar to us now are that these "frequency records" had either sustained tones or sliding tones that were, supposedly, scientifically generated and that the speeds of those old-time 
record turntables could be varied by hand; for in Cage's mind, when he wrote this piece, were certain unprecedented capabilities of the new radio studios. A few years later, Cage was commissioned to produce "music" for Kenneth Patchen's radio play, He Wears a Slouch Hat; and what he wanted to do here likewise presaged future work: "Take the sounds out of the play, and make the music out of those sounds." A dozen years later, he premiered Imaginary Landscape IV (1951) for twelve radios and twentyfour performers, one manning the volume-control of each machine and another changing the stations, in response to Cage's scored instructions.

The second strand behind Cage's recent radio art was his early interest in audiotape, which is so familiar to us now that we tend to forget it became commonly available only after World War II. Prior to that, sound was recorded on continuous wire that, while it could be cut, could not be spliced easily. That is, its parts could not be reassembled without making thunderous telltale sounds. Precisely because tape, by contrast, could be spliced gracefully, sounds separately recorded could be fused together without distracting interruptions.

Cage remembers that when the French composer Pierre Schaeffer first introduced him to audiotape in 1948, he rejected its possibilities; but within a few years, he was working on Williams Mix (1953), which I consider the principal neglected masterpiece in the Cage canon. Here sounds were gathered on tape from a universe of sources, and these tapes were cut into small pieces, some much shorter than audiotape is wide, and then mixed with each other into an aural pastiche that is continually leaping, with unprecedented shifts, from one kind of sound (and one acoustic space) to another. To complicate the audio experience yet further, Cage required that eight tapes be made, and then that any or all of them could be played simultaneously. On the only recorded performance of this work (on the twenty-five-year retrospective album [1958] that is still available), all eight taped "voices" are heard.

Cage's first work for Schöning began with the latter's invitation to read aloud one of his recent $W$ ritings Through Finnegans $W a k e$. These are a series of Cagean texts in which he extracts sequentially certain words from Joyce's classic and then sets them on mesostic axes composed of the name of James Joyce. (If the vertical axis of an acrostic is flush left, a mesostic has its axis in the middle.) In Writing for the Second Time Through Finnegans Wake, which he chose to read for WDR, the opening is: 
wroth with twone nathandJoe

A
Malt
Shem
pftJschute
sOlid man
that the humpt Yhillhead of humself
is at the knoCk out
in thE park

Asked to add a "musical background" to this declamation, Cage decided to gather sounds recorded in every geographic place mentioned in Joyce's text. For guidance, he consulted Louis Mink's recent $A$ Finnegans $W a k e$ Gazetteer. By birth a prodigious correspondent, Cage wrote friends around the world and asked Schöning to do likewise; but since most of Joyce's places were in Ireland, he decided to spend a whole month there himself, recording not only places but native musics. This strategy recalls his proposal for the Kenneth Patchen radio play - to extract the acoustic references from the text itself and to compose music from those worldly sounds. All these field recordings were then gathered at IRCAM in Paris, where Cage spent a month (and, by design, only a month) assembling them by chance operations into dense mixes, at once cacophonous and euphonious, that, while they may vary in detail, are roughly similar for the entire duration.

Whereas some Cage pieces have been much less than music used to be, others have been much more; for Cage has been at different times a prophet of both minimalism and abundance. This Joycean radio piece, entitled Roaratorio (1979), falls securely into the second tradition. The continuous bass is the sound of Cage himself reading. On top of that is an abundant mix of sounds reminiscent of Williams Mix (as Cage now realized on multitrack tape the effect of playing several monophonic tapes simultaneously); but whereas nothing in that earlier piece has a sustained presence, in this new one the sounds of Irish music tend to stand out from the mass. In that last respect, Roaratorio structurally resembles HPSCHD (1969), which has always stood for me as the earlier masterpiece of Cagean 
abundance. In that earlier piece, beneath the continuous microtonal din is the sound of seven harpsichords, playing harpsichord selections from Mozart to the present; and in the single available recording (Nonesuch, 1969), these harpsichords tend to stand out from the mix to the same degree that Irish music does in the new piece. In one sense, this subtle predominance compromises Cage's aleatory methods; yet in both pieces, it also reveals compositional decisions about components that were made well before the aleatory methods were exercised.

His next major piece for WDR, Ein Alphabet (1982), also began with a text that (unlike before) was translated into German. Most of "James Joyce, Erik Satie, Marcel Duchamp: An Alphabet" consist of mesostics that Cage wrote out of his own head on the names of these three heroes, all of whom, in Cage's curious judgment, have made works that "resisted the march of understanding and so are as fresh now as when they first were made." Interspersed among the mesostics are long passages from the writings of each of these men. (The whole original English text appears, along with Cage's spiky preface, in his recent collection of writings, $X$ [Wesleyan University Press, 1983].) Even though I share Cage's overwhelming admiration for the Wake, I have come to prefer, as poetry to be read, those mesostics that are written wholly out of his own head.

The WDR production honors the conventions of traditional radio theater in that certain roles were assigned to various performers - the French musicologist Daniel Charles reading Satie (in inept German), the American artist George Brecht representing Duchamp (in better German), Cage himself reading Joyce (in the original neologistic superEnglish). As the narrative passes through various scenes, their settings are occasionally reinforced with sound effects that tend to be very abrupt, usually sketching a scene suggestively (rather than filling it in). As other figures are included, their voices are represented by yet other performers speaking GermanDick Higgins as Robert Rauschenberg, Christian Wolff as Henry David Thoreau, Buckminister Fuller as himself, etc.

Ein Alphabet reflects the arrival of audiotape in that it was composed from many parts that were separately recorded (in fact, on two continents, at different times). Insofar as I can understand German, I think the work very good, filled with interesting departures within the tradition of radio plays, as well as suggestive moves that others can adopt (not the least of which is the imaginary conversation among historic figures who did not 
know one another). On the other hand, Cage himself tends to dislike all the leaps from scene to scene. "All those scenes," he recently told me, "have beginnings and ends. That's what annoys me." In my interpretation, this caveat means that Ein Alphabet lacks the uninflected, nonclimactic structure that, in all media, has been the signature of Cage's work.

Muoyce (1983) is a more familiar Cagean performance-essentially a solo reading of his Writing for the Fifth Time Through Finnegans Wake; but to complicate the largely uninflected declamation, Cage decided to use a multitrack audiotape device he had used before (mostly in live performance). The first of the piece's four parts has him whispering the same text simultaneously four times all the way through, in a nonsynchronous chorus; the second part is a self-trio; the third part, a duet; the fourth (and shortest) part, a solo. He interrupts his whispering for full-voiced speaking only when the original text had italics. Here, as well in the previous work that resembles it, "Empty Words" (1974-75), I have personally come to find this minimalism trivial. Always true to his principles, Cage says, "I find this one easier [than Ein Alphabet]. What makes this easy for me is that the quiet sober mind is assumed and is not disturbed, even by the lightning imitations which come through the loud interrupting sounds, because they don't really interrupt. Once they are gone, the whispering continues."

HMCIEX (or HCE-mix, with its letters alternating) was commissioned by both WDR and International Composers in Los Angeles; and even though it is a dense mix, it is also a simple piece (that, contrary to Cage's esthetics, does not resist understanding). In honor of the Olympics, it is an international pastiche of folk songs (and in that respect reminiscent of Karlheinz Stockhausen's similarly ecumenical Hymnen [1979]; but whereas Stockhausen favored western sources, Cage draws more upon the Third World). One quality that separates HMCIEX from Cage's earlier mixes is that its sources are longer, and thus more often identifiable upon first hearing. A second problem is that, given such long excerpts, the sound often falls into a regular beat that is utterly contrary to Cage's esthetics. Compared to Roaratorio, HMCIEX is a slighter work, charming nonetheless.

What Cage has done in his radio art is define other possibilities for presenting recorded sound, and thus other ways of making records. When Cage has been criticized for releasing records that were "not as good" as live performances of his work, the reply was that, aside from Williams 
Mix, Cage's music has not been written for tape. Now, given the demands of modern radio, he is composing for tape, and exploiting its unique capabilities, to make works that are true both to tape and his esthetics and, in my opinion, has produced, at least in Roaratorio, a transcription as good as any of his earlier records.

In this last respect, Cage discovered a truth that another adventurous North American musician also made sometime before him - the Canadian pianist Glenn Gould. Frustrated as a composer, unwilling to do live performances, Gould made in Toronto a series of radio features, scarcely heard here, that represent to my mind the best radio art ever produced in North America; for with multitrack audiotape, Gould could mix speech with speech, speech with music, and music with music, not only in ways that, given his materials, would be impossible in live performance but in fugal arrangements that would also be beautiful. In other words, invitations from radio stations forced both these verbal musicians to compose for tape as they had not composed before, producing valuable work that, if not for these radio invitations, probably would not have otherwise happened. One truth that strikes me from the success of these two artists is that, even in performance arts, it is best to work as writers and painters have traditionally worked - with no more than one assistant.

The principal reason why this essay has been so introductory is that it talks about works that are not commonly available. Whereas $W$ illiams Mix is included on that three-record memento of the 1958 25th Anniversary Concert (from New Music Distribution in NYC), Roaratorio is found only in a thoroughly bilingual box by the same title that was published by Athenäum Verlag in Königstein/Ts in Germany. In this box are a cassette copy of the work, prefaced by Cage's reading part of the text alone, and succeeded by a short interview in English with Schöning; a book about the work (that includes the text of a longer interview with Schöning); and a fold-out score that hides as much as it reveals. Ein Alphabet has never been aired here (and probably won't be, given our bias against broadcasting anything in foreign languages, other than operas). Since HMCIEX was co-commissioned by a Los Angeles outfit, it has been broadcast occasionally on our public radio stations. In truth, most of us can scarcely begin to grasp Cage's achievement as a horspielmacher until all of his radio art is gathered between a single set of covers. 